\title{
Discentes descritos com deficiência intelectual (DI): as permissões de suas expressões sexuais na escola e as representações existenciais de seus docentes
}

Described students with intellectual disabilities (ID): the permissions of their sexual expressions at school and the existential representations of their teachers

Los estudiantes descritos con discapacidad intelectual (DI): los permisos de sus expresiones sexuales en la escuela y las representaciones existenciales de sus profesores

\author{
Hiran Pinel \\ Professor doutor na Universidade Federal do Espírito Santo, Vitória, Espírito Santo, Brasil. \\ hiranpinel@gmail.com \\ ORCID - https://orcid.org/0000-0002-8540-6653
}

Paulo Roque Colodete

Doutor pela Universidade Federal do Espírito Santo, Vitória, Espírito Santo, Brasil. parocolodete@gmail.com

ORCID - https://orcid.org/0000-0001-6421-1868

\section{Rodrigo Bravin}

Doutorando na Universidade Federal do Espírito Santo, Vitória, Espírito Santo, Brasil. rodrigobravin@gmail.com

ORCID - https://orcid.org/0000-0002-2661-3513

Recebido em 23 de julho 2020

Aprovado em 30 de setembro de 2020

Publicado em 26 de outubro de 2020

\section{RESUMO}

Este texto objetiva descrever e analisar algumas Representações Existenciais (RE) (PINEL, 2012; 2018) de 07 (sete) professores/professoras de uma escola pública capixaba acerca da sexualidade de seus/ suas discentes jovens com deficiência intelectual. Para isso, nos apoiamos no método fenomenológico-existencial e a produção de dados aconteceu em dois momentos: no primeiro os participantes responderam em uma folha de papel como percebiam a sexualidade de um (a) estudante descrito com Deficiência Intelectual. No segundo, e a partir das respostas, foram realizadas conversas individuais com cada um deles. A Deficiência Intelectual (DI) e a sexualidade de jovens têm sido reconhecidas como experiências com as quais professores e educadores podem desvelar dificuldades em lidar na sala de aula escolar, assim como a não escolar. Tais problemáticas dos mestres podem ser alguns dos impeditivos para se promover efetivamente a inclusão. Em geral, as respostas dadas pelos professores se mostraram rígidas colocando o aluno com DI nos extremos de ser ou assexuado ou hipersexuado. Vale destacar que um dos profissionais reconheceu a sexualidade como algo comum aos seres humanos e parte de seu desenvolvimento.

Palavras-chave: Deficiência Intelectual; sexualidade; escola inclusiva. 
http://dx.doi.org/10.5902/1984686X48341

\section{ABSTRACT}

This text aims to describe and analyze some Existential Representations / RE (PINEL, 2012; 2018) of 07 (seven) teachers from a public school in Espírito Santo about the sexuality of their young students with intellectual disabilities. For this, we supported ourselves in the phenomenological-existential method and the production of data happened in two moments: in the first, the participants answered on a sheet of paper how they perceived the sexuality of a student described with Intellectual Disability. In the second, and based on the responses, individual conversations were held with each of them. Intellectual Disability (ID) and young people's sexuality have been recognized as experiences with which teachers and educators can reveal difficulties in dealing in the school classroom, as well as the nonschool one. Such problems of the masters can be some of the impediments to effectively promote inclusion. In general, the responses given by the teachers were rigid, placing the student with ID at the extremes of being either asexual or hypersexuited. It is worth mentioning that one of the professionals recognized sexuality as something common to human beings and part of each person's development.

Keywords: Intellectual Disability; sexuality; inclusive school.

\section{RESUMEN}

Este texto tiene como objetivo describir y analizar algunas Representaciones existenciales / RE (PINEL, 2012; 2018) de 07 (siete) maestros de una escuela pública en Espírito Santo sobre la sexualidad de sus jóvenes estudiantes con discapacidad intelectual. Para esto, nos apoyamos en el método fenomenológico-existencial y la producción de datos ocurrió en dos momentos: en el primero, los participantes respondieron en una hoja de papel cómo percibían la sexualidad de un estudiante descrito con discapacidad intelectual. En el segundo, y en base a las respuestas, se mantuvieron conversaciones individuales con cada uno de ellos. La discapacidad intelectual (ID) y la sexualidad de los jóvenes han sido reconocidas como experiencias con las cuales los maestros y educadores pueden revelar dificultades para tratar en el aula escolar, así como en la no escolar. Tales problemas de los maestros pueden ser algunos de los impedimentos para promover efectivamente la inclusión. En general, las respuestas dadas por los maestros fueron rígidas, colocando al estudiante con identificación en los extremos de ser asexual o hipersexual. Vale la pena mencionar que uno de los profesionales reconoció la sexualidad como algo común a los seres humanos y parte del desarrollo de cada persona.

Palabras clave: Discapacidad Intelectual; sexualidad; escuela inclusiva.

\section{Introdução}

O objetivo deste texto é descrever a analisar algumas representações existenciais (PINEL, 2012, 2018) de 07 (sete) professores / professoras de uma escola pública capixaba acerca da sexualidade de seus/ suas discentes jovens com deficiência intelectual.

A sexualidade, em nossa sociedade (e cultura), muitas vezes é acompanhada de algum preconceito, senão vários, e isso tende a se acentuar quando o sujeito dessas discriminações é rotulado ou diagnosticado médica e psicologicamente com Deficiência Intelectual (DI), como bem destacaram Drago, Colodete e Pinel (2015) e Pinel et al. (2015). 
http://dx.doi.org/10.5902/1984686X48341

Lidar com a sexualidade do aluno e/ou educando com DI pode ser reconhecida como uma experiência com a qual professores e educadores desvelam dificuldades, o que implica em problemas na condução e administração na sala de aula escolar e não escolar (BEIRAS; TAGLIAMENTO; TONELI, 2005), sendo esse um dos possíveis impeditivos e anteparos para se promover efetivamente a inclusão (MOURA; CAVALCANTI, 2014).

Mas a escola tem sido considerada como uma instituição para todos e todas - um direito. Porém, como se percebe, ainda encontramos problemas como de matrícula para todos e todas, permanência e efetiva aprendizagem dos discentes (PINEL, 2012).

Mas quem é essa pessoa que será diagnosticada, corretamente (ou não) com DI? Será o próprio Drago (2012, 2013), e Drago e Pinel (2014), que irão destacar as vicissitudes enfrentadas pelo aluno (e/ou educando) com DI dizendo,

[...] que, entre o grupo de pessoas com deficiência (mental, visual, auditiva, cegas, surdas, dentre outras), as que enfrentam mais barreiras em relação à inclusão nas salas comuns da educação em todos os seus níveis são aquelas que apresentam deficiência mental e transtornos globais do desenvolvimento, o que inclui as pessoas com Síndromes de Down, Autismo, Asperger, Williams, dentre outras (DRAGO, 2013, p. 243).

Também denominado, muitas vezes, no senso comum, de Retardo Mental (RM) e de Deficiência Mental (DM) em algumas classificações popularizadas, esse quadro, o de DI, destaca um sujeito que primordialmente pode se apresentar com antecedentes de problemas neurobiológicos (VASCONCELOS, 2004) e fatores hereditários.

Descrita por médicos como problemática, o diagnóstico de DM ocasiona consequências. No caso da Educação Especial, assume uma perspectiva inclusiva e se denomina de Deficiência Intelectual - DI.

O termo DI descreve melhor ao professor algo concretamente ligado à sua prática (e possivelmente práxis) pedagógica e psicopedagógica. O discente com DI é antes de tudo uma pessoa total (holística), e a sexualidade dela é uma das facetas do seu existir como "ser no mundo". E é uma das mais vitais da existência (humana), por estar envolvida por forte repressão advinda da sociedade e da cultura, por evocar práticas religiosas condenatórias de sua expressão, relacionadas com questões de moralidade presentes na mídia, por exemplo.

Nosso foco aqui é investigar a sexualidade de um outro, o aluno descrito medicamente com DI, ao olhar e percepção de sentido da professora/ professor - a percepção fenomenológica desse profissional do seu vivido com esse (a) estudante. 
http://dx.doi.org/10.5902/1984686X48341

A expressão da sexualidade, numa sociedade repressora, tem sido considerada como um fator que pode perturbar o desenvolvimento e a aprendizagem, algo de impacto no desempenho acadêmico, quando o jovem discente é descrito como DI, estando ele na sala de aula regular e ou no Atendimento Educacional Especializado (AEE), algo realizado pela Educação Especial numa perspectiva inclusiva.

Entretanto, a sexualidade é ainda um tabu em muitas culturas, sociedades - a escola e seus agentes não estão livres de preconceitos, discriminações e formação de estigmas. Há mesmo um movimento em resistir contra o desenvolvimento de práticas didáticas inventivas e criativas escolares, que abordem a sexualidade desses alunos e/ou alunas. Existe um temor: a sexualidade nos ameaça, e no máximo, o que pode acontecer dentro do aparelho escolar é a biologização daquilo que é sexual, e que carece de ser abordado nos aspectos afetivos, sensitivos, prazerosos, orgásticos, etc.

Vale ressaltar, diante do contexto apresentado de repressão à sexualidade, que a Lei Brasileira de Inclusão das Pessoas com Deficiência (BRASIL, 2015) reconhece que a capacidade civil desses sujeitos não é afetada plenamente pela deficiência. Assim, devem ser garantidos, sempre, seus direitos sexuais e reprodutivos, a decisão sobre casamento ou constituição de união estável, formação de família, adoção, fertilidade, esterilização, entre outros.

Há ainda o Relatório Mundial sobre Deficiência (OMS, 2011) que defende o direito à educação sexual para as pessoas com deficiência, principalmente para as que têm DI, pois os dados apresentados indicam que elas estão mais vulneráveis às situações de abuso sexual. Além disso, o acesso à aprendizagem sobre sexualidade é apontado como uma ferramenta potente para promoção de experiências prazerosas em relação ao sexo a aos relacionamentos afetivos.

\section{Revisão de literatura}

\section{Representações $^{1}$}

Nosso objetivo aqui-agora é o de produzir uma pequena revisão de literatura que abarque nossa temática de modo direto ou não. Escolhemos intencionalmente três livros e dez artigos científicos.

Kropotkin (1998, p. 51) diz que a questão vital do jovem é "O que eu me tornarei?". Partindo da premissa de que o processo de ensino e aprendizagem depende de uma relação professor-aluno mais inventiva e provocativa, os preconceitos contra as expressões 
http://dx.doi.org/10.5902/1984686X48341

sexuais de alunos/alunas com DI só tenderão a facilitar ao jovem discente tornar-se algo desumano impregnado de coisificação, com autoestima baixa.

Giami (2004) estudou as Representações Sociais (RS) das diferenças, focando nos temas sexualidades e deficiência mental (ou intelectual, termo que preferimos como já explicado), e para isso coletou dados, detectando como algo problemático entre pais e professores em relação às pessoas com DI internadas em quatro instituições, evento totalizante (GOFFMAN, 2001). As conclusões do autor, quanto aos educadores, podem ser assim sintetizadas: há uma complexa RS de que os indivíduos com DI têm uma sexualidade mais selvagem (algo descontrolado) e de difícil educação, mesclando numa representação de que eles são inibidos e embotados. Já quanto aos pais: as RS destacam de modo acentuado os componentes afetivos de seus próprios rebentos, tornando-os dessexualizados, crianças "ad eternas".

Segundo Kempton (1983), a associação DI e sexualidade faz emergir um conjunto de atitudes por parte dos pais e dos profissionais que favorecem muito mais a repressão da sexualidade desses jovens do que a sua experiência que é saudável. Esse autor então classifica três tipos de atitudes diante da sexualidade desses sujeitos : a) os jovens são eternas crianças; b) são seres infra-humanos (seres grosseiros com instintos animalescos); e, c) pessoas em desenvolvimento: sujeitos com desenvolvimento sexual diferenciado da maioria, mas normal e algo comum, o social e historicamente dito normal; Maia e Camossa (2002), por sua vez, trabalharam com jovens deficientes mentais intelectuais escutando deles relatos sobre a sexualidade, e para isso criaram e aplicaram diversos instrumentos que facilitaram as expressões orais desses sujeitos: 1) Desenho da Figura Humana; 2) Apresentação de bonecos da família sexuada; e, 3) Apresentação de pranchas dos temas: namoro, casamento, masturbação, jogos sexuais, menstruação, relação sexual, gravidez, parto, amamentação e abuso sexual. As autoras concluíram que esses jovens: a) têm noção de identidade e papéis sexuais; b) diferenciam e nomeiam órgãos sexuais humanos, especialmente o órgão sexual masculino adulto; c) apesar de conseguirem nomeá-los, nem todos sabem sua função; e, d) com frases curtas e objetivas mostraram os conceitos sobre os diferentes temas apresentados.

Maia e Ribeiro (2010) são autores que abordam, num estudo, as ideias preconceituosas sobre a sexualidade de pessoas/ discentes com DI, discorrendo, de modo crítico e reflexivo, sobre diversos mitos, tais como: 
http://dx.doi.org/10.5902/1984686X48341

(1) pessoas com deficiência são assexuadas: não têm sentimentos, pensamentos e necessidades sexuais; (2) pessoas com deficiência são hiperssexuadas: seus desejos são incontroláveis e exacerbados; (3) pessoas com deficiência são pouco atraentes, indesejáveis e incapazes para manter um relacionamento amoroso e sexual; (4) pessoas com deficiência não conseguem usufruir o sexo normal e têm disfunções sexuais relacionadas ao desejo, à excitação e ao orgasmo; (5) a reprodução para pessoas com deficiência é sempre problemática porque são pessoas estéreis, geram filhos com deficiência ou não têm condições de cuidar deles (p. 1).

$\mathrm{O}$ ato de acreditar nesses mitos, como se verdades fossem, e que assim se cristalizam, desvela um modo preconceituoso e estigmatizante de entender e de compreender a sexualidade de discentes com deficiência em geral, e especificamente com DI, como sendo desviante. Mas esse desvio só o é, a partir de padrões definidores de normalidade $\mathrm{e}$ isso se torna um anteparo ou barreira para a aprendizagem e o desenvolvimento de vida afetiva e sexual plena dos sujeitos que são alvos de preconceitos.

Nesse caminho, Bastos e Deslandes (2005) fazem uma revisão bibliográfica sobre o tema sexualidade e o adolescente com deficiência intelectual (in)dissociado às repercussões familiares do adolescer. Os resultados obtidos mostram que a adolescência apresenta grandes desafios aos pais na tarefa de integrar socialmente seus filhos com deficiência, especialmente, quando a sexualidade começa a aflorar.

Os trabalhos pesquisados reforçam que os preconceitos em relação à sexualidade estão presentes. Há ainda medo da família e dificuldade em lidar com a possiblidade dos adolescentes exteriorizarem comportamentos sexuais e que eles tenham como consequências o abuso sexual e a gravidez. As autoras defendem a necessidade de estender o debate para os pais, mães e filhos com deficiência, de modo que esses adolescentes possam viver a sexualidade de forma segura, sem estigmas e com satisfação.

Moura e Cavalcanti (2014) também fizeram um estudo bibliográfico objetivando pesquisar os modos como pais e professores pensam, sentem e agem na sexualidade de discentes com deficiência mental e DI na escola. A partir daí levantaram duas interrogações: 1) Existem mitos e estereótipos a respeito da sexualidade nas pessoas com DI?; 2) Como a temática sexualidade vem sendo abordada no ambiente escolar?

Os autores concluem que o tema tal qual se propõem estudar ainda é pouco produzido e ao responder cada questão: 1) encontraram apenas dois artigos que abordam a temática; esses artigos apregoam ações contra os mitos e estereótipos que só prejudicam o desenvolvimento e aprendizagem escolar dos sujeitos com DI; as pessoas com DI são vistas como anjos (puras, sacrossantas) e feras (hipersexuadas, demoníacas); 2) 
http://dx.doi.org/10.5902/1984686X48341

encontraram também apenas dois artigos; a inclusão escolar está distante de ser efetivada, mas os professores andam cuidando de si e aceitando mais as diversidades; a discussão sexual é mais comum entre discentes do que entre professores; o tema é pouco debatido ainda, pois causa preconceito e vergonha; no âmbito da Educação Especial pouco tem sido realizado no que se relaciona à sexualidade nos DI - e isso ocorre também em escola comum.

Para Maia (2001) a sexualidade é parte indissociada de todo o ser humano e sua manifestação independe da presença ou ausência de uma ou mais deficiências - é ser humano, tem sexualidade e a expressa de algum modo. A importância desse tema na investigação em Educação Especial, concordamos com a autora, acontece se objetivamos buscar ações alternativas de orientação mais adequadas, pertinentes e éticas - e estéticas, nós acrescentaríamos, isto pelo fato de que Comumente a família, os profissionais e os professores, seja por ingenuidade, desconhecimento ou ainda por despreparo, tratam a sexualidade de acordo com crenças, preconceitos e ideias distorcidas, atribuindo aos deficientes uma sexualidade com limitações ou com exageros. As possíveis elaborações de programas de orientação sexual demandariam preliminarmente uma investigação sobre as concepções que os educadores têm acerca da sexualidade das pessoas com deficiência. Isso possibilitaria acréscimos metodológicos (de conteúdo e de estratégias) para consolidar futuras propostas de ações educativas voltadas à sexualidade do deficiente, seja qual for a condição da deficiência e sua possível limitação social (MAIA, 2001, p. 35).

\section{Intervenções}

Furlani (2011) classifica as abordagens atuais para intervenção/ interferência em Educação Sexual, descrevendo-as em [1] biológica-higienista, a [2] moral-tradicionalista, a [3] terapêutica, a [4] religiosa-radical. E, depois, a autora prossegue citando as abordagens mais positivas, ou seja, as mais planejadas contemporaneamente, isso quando o professor está interessado em superar visões moralistas, do conteudismo biológico (e da higiene), do sentido de considerar toda expressão sexual uma doença psicológica e orgânica, do fundamentalismo religioso: a dos [5] direitos humanos, a dos [6] direitos sexuais, a [7] emancipatória e finalmente a mais ousada e inventiva que é a [8] queer. Essas últimas quatro abordagens da/ na Educação Sexual, em nossa opinião, podem estar (e estão) ligadas diretamente também ao discurso e práxis de Paulo Freire (2005).

Paulo Freire tem sido um pensador da Educação e da Pedagogia também interessado no outro, esse outro entregue às relações sociais advindas da sociedade/ história/cultura, do sujeito que é ser no mundo, que pode ser consciente de si (junto ao outro) e que demanda lutar por seus direitos gerais, e aqui destacamos os sexuais, e acima de tudo a emancipação como cidadão, que é sendo na sua luta diária. Entendemos que a categoria 
http://dx.doi.org/10.5902/1984686X48341

freireiana emancipação pode se provocadora de uma educação sexual consciência, livre, humana (do "ser mais"), em um espaço dialógico e da palavra - dentre outros.

Costa (2000) é, na época do seu artigo, uma quartanista de um curso de Psicologia, e monta um programa de Orientação Sexual para jovens com deficiência de uma escola estadual comum - em sala inclusiva. Os discentes tinham paraplegia, paralisia cerebral e paralisia infantil. Para a autora, incluir,

[...] não é negar as diferenças, mas desvendá-las no processo social, como diferentes do padrão, compreendendo esse padrão como uma referência construída pelos homens nas relações sociais. Incluir então implica em 'desnaturalizar' (COSTA, 2000, p. 54).

A intervenção da autora junto ao grupo de quatro (04) estudantes com deficiência objetivou ir contra os preconceitos e tabus, que ela assim descreve: produzir uma ação visando interromper o "processo de exclusão que vai se construindo ao longo da vida e do processo educacional" (p. 54), e isso significa,

(...) dar início a um novo caminho, no qual, em parcerias com os alunos, podem-se debater os preconceitos, as limitações impostas pela deficiência, e, ainda, os tabus que são criados; discutir a sexualidade na forma como se apresenta em uma sociedade, e nas possibilidades de ser vivida por cada um de nós, com nossas características pessoais, apresentem elas deficiências/diferenças ou não (COSTA, 2000, p. 54).

A produção de oficinas de orientação sexual numa escola inclusiva é um trabalho positivo, que acabou por nos dar duas pistas indispensáveis nessa esfera da educação sexual de pessoas com DI: a de que a escola demanda articular-se com o conteúdo social, de modo crítico, emancipatório, e a de que, a partir daí, possamos entender e compreender "[...] o processo de construção histórico-social (da escola e da sociedade) para chegar ao ponto em que estão. Neste sentido é possível cogitar e trabalhar a sua transformação" (COSTA, 2000, p. 1).

Leão e Ribeiro (2007) tiveram por objetivo esboçar uma produção textual e refletir a questão da orientação sexual no cenário inclusivo, e para isso consultaram artigos, dissertações, teses e livros que versavam sobre os temas da inclusão e sexualidade, aspectos estes inter-relacionados e indissociáveis, afirmando que a temática sexualidade é uma das várias que podem contribuir para a inclusão das pessoas com deficiência pelo fato de estar ligada de forma muito maior ao processo de exteriorização de sentimentos, valores e atitudes do que necessariamente aos conteúdos acadêmicos e científicos que devem ser aprendidos pelos estudantes. 
http://dx.doi.org/10.5902/1984686X48341

Os autores encontraram dados que dão potência à construção de um programa de escola que busque, dentre suas propostas, promover a orientação sexual, pois o corpo do aluno e da aluna desvela sentidos em todos os espaços, e também na escola - o corpo pontua inclusive a sexualidade como necessidade básica no seu existir.

Prioste (2010) diz, e com ela compactuamos, que sobre o tema da sexualidade, apesar de ter se ampliado e tornado objeto de reflexões e até de mudanças, se percebe que as manifestações sexuais continuam sendo tema tabu para professores, e isso se amplia quando a sexualidade é de estudantes que são abordados pela Educação Especial numa perspectiva inclusiva, seja na sala de aula regular, acompanhados (ou não) de Atendimentos Educacionais Especializados - AEE - ou "crianças com necessidades educacionais especiais" (PRIOSTE, 2010, p. 14). A autora trabalhou sob um foco psicanalítico junto a 28 (vinte e oito) professores e professoras, divididos em dois grupos durante a Hora do Trabalho Pedagógico Coletivo - HTPC. Das 16 reuniões, as preocupações foram se centrando em Luciene, 16 anos de idade, com Síndrome de Down, inserida em classe comum/regular.

No referido artigo a autora produz a análise dos dados dos discursos dos mestres, inferindo que as explicações dos professores, em relação à sexualidade de Luciene, tinham como fundamento uma perspectiva biologizante. Essa visão equivocada tinha como consequência o entendimento que os comportamentos sexuais da moça eram em decorrência da Síndrome de Down e, por isso, a culpa era de seu pai e de sua mãe que não a ensinavam. Nesse exemplo, fica evidente que esses profissionais entendem que a educação sexual é obrigação da família, ou de um especialista, mas nunca da escola (PRIOSTE, 2010).

\section{Metodologia}

Diante do exposto anteriormente, o objetivo desse artigo é o de descrever e analisar algumas Representações Existenciais/ RE (PINEL, 2012; 2018) de professores/ professoras de uma escola pública capixaba acerca da sexualidade de seus/ suas discentes jovens com DI.

Representação Existencial (RE), diz-nos Pinel (2012; 2018), pode ser entendida aquiagora como um ato-sentido de representar algo, que de tão fortemente vivido no existir e na existência encarnados, acaba se tornando uma realidade possível, pois vivida, algo concreto que a linguagem desvela e desmascara, anuncia e denuncia a humanização e a 
http://dx.doi.org/10.5902/1984686X48341

desumanização. Pode ser algo inventado, mas criado, algo produzido e criado, sim, um fenômeno que sempre aparece a nos tocar.

Objetivamos uma "pesquisa de Representação Existencial" (PINEL, 2012; 2018) que nos reporta à possibilidade de estudá-la por um método de inspiração fenomenológicoexistencial. O termo representação não é uma mentira, ou se for, é uma mentira factual, uma mentira verdadeira, já enfiada na carne do sujeito, e ele não sabe, ou não se permite sentir, pensar e agir mudando-se e ao outro:

No existir da pessoa há um simbólico palco, algo como uma mandala, a convidá-lo a representar algo que sua carne absorveu, algo que o fere ou o alegra, que não é só harmonia e integração, mas conflito, dor, sofrimento, lágrimas, desintegração, um corpo que se esfacela no ar. A mandala é esse campo, esse círculo mágico e que concentra energias positivas, negativas e as duas efervescências juntas e indissociadas, "positivasnegativas". Estudar e pesquisar as RE, e considerando o termo representações nesse sentido, é trazer a lume a carne humana (com o outro/ outros no mundo), é provocar ao leitor a encontrar, e só entrar procurar sentido de ser da vida. (...) A RE nos diz mais do ator encarnado, que se mistura tanto com os personagens vividos numa sociedade difusa, injusta, capitalista, maquiavélica, perversa, alegre, saudável, humanizante, desumanizadora etc. [...] (PINEL, 2018, p. 4).

Em Pinel (2012) encontramos que o método de pesquisa da Representação Existencial - RE (PINEL, 2018) parte do princípio que o ser sendo junto ao outro no mundo, ele mesmo foi jogado na sociedade/ cultura/ história sem sua anuência explícita, e a sua tarefa aqui-agora é a de viver e se relacionar nesse mesmo mundo, fazendo-o com a responsabilidade mínima e necessária na "com+vivência" com o outro e outros (no mundo), criando/ produzindo/ inventando ações de sentido junto a esse outro, que é também parte integrante de si, mesmo que negue.

Essas ações, não raras vezes, são preconceituosas também - não só, mas também. Trata-se, nessa modalidade de pesquisa, de compreender as Representações Existenciais (2018) criadas pelo sujeito (ou pelos sujeitos) no seu existir no mundo, "ser no mundo" que é sendo, colocando-se sempre em um "envolvimento existencial" (epoché) com o fenômeno representacional encarnado (PINEL, 2018), pois vivido na "pele-alma-mente" dele, ao mesmo tempo, se "distanciando reflexivamente" (eidos), produzindo significados sentidos acerca do que existiu na sua carne, que insiste em solidificar-se, mas que pode ser diluída ou não (PINEL, 2012, p. 97).

Prossegue Pinel $(2012 ; 2018)$ ao recomendar os passos gerais para realizar estudos do que denominamos de pesquisa da Representação Existencial que são: 
http://dx.doi.org/10.5902/1984686X48341

[...] 1) uma postura constante de "envolvimento existencial" e "distanciamento reflexivo" (FORGHIERI, 2001) do fenômeno dado [...]; 2) escolha do tema de pesquisa ou interrogação acerca dessa mandala que brota e dela percebemos fenomenologicamente figuras/ FI e fundos/ FU de algo teorizamos e chamamos de RE; 3) elaboração do projeto de pesquisa [...]; 4) fazer inúmeras leituras dos depoimentos/ livros/ imagens etc., dos mais diversos modos, através de sistemática postura/ atitude de envolvimento e distanciamento do fenômeno - postura que acompanha todo o processo[...]; 5) procura cuidadosa de criar Guias de Sentido - GS - um guia sempre inconcluso, incompleto, inacabado e validado pela vivência e experiência do outro com o outro, no mundo; 6) escrita do texto científico [...] (PINEL, 2018, p. 5-6).

Assim, foram produzidos dados de cinco professoras e dois professores com idades entre 30 e 50 anos, todos com curso superior completo nas áreas de Língua Portuguesa, Artes, Geografia, História, Matemática, Inglês e Educação Física e com pós-graduação lato sensu (sendo duas com o título de mestrado). A experiência média dos profissionais varia entre 08 e 15 anos de atuação no magistério e todos eles vivenciam, no momento, a presença de um aluno com Síndrome de Down na $8^{\mathrm{a}}$ série $\left(9^{\circ}\right.$ ano) do ensino fundamental de uma mesma escola pública situada na Grande Vitória, Espírito Santo. Como parte do cumprimento da ética na pesquisa, os sete profissionais foram identificados pelos codinomes: Professora 1, Professora 2, Professora 3, Professora 4, Professor 5, Professora 6, Professor 7.

Foi entregue a cada sujeito uma folha de papel A-4 e nela digitada um quesito interrogativo, que mesmo incipiente oferece possibilidades de compreensão acerca do tema: A partir de suas experiências na sala de aula, do seu existir como professor, como é a sua representação da sexualidade de um aluno ou aluna descrito/a com Deficiência Intelectual?

Conversamos individualmente com cada profissional acerca das respostas escritas e, com autorização, gravamos esses encontros, onde objetivamos capturar os sentimentos e os pensamentos (e gestos) quando responderam ao quesito. Pudemos complementar. Coletamos e produzimos tais dados independente do conceito deles do que seja DI - se científico ou não. De posse das respostas escritas nas folhas e da transcrição de cada conversa individual, fizemos uma análise detalhada criando temas / categorias que chamamos de Guias de Sentido (GS), surgidas a partir das RE dos professores, que foram: a) infantilização da sexualidade dos estudantes com DI, b) desumanização / julgamento da sexualidade dos estudantes com $\mathrm{DI}$ e c) reconhecimento da sexualidade dos estudantes com DI como direito e parte do desenvolvimento humano saudável, e então produzimos uma análise existencial com base nos autores que fundamentam esse artigo. 
http://dx.doi.org/10.5902/1984686X48341

No sentido fenomenológico que considera o ser no mundo, entendemos que as classificações de problemas humanos, um tema caro à Psicopatologia, só têm significado dentro de um contexto cultural, social e histórico. Os problemas, os transtornos, os desvios, apenas assim o são, quando apoiados por esses contextos.

Outros contextos diferenciados não considerariam "isso-daí" que pontuamos, como doenças, patologias etc. Concordamos com Foucault (1975, p. 71) de que "um fato tornouse, há muito tempo, o lugar comum da sociologia e da patologia mental: a doença só tem realidade e valor de doença no interior de uma cultura que a reconhece como tal". Outro aspecto das classificações e dos diagnósticos é que, em nossa opinião, eles servem se nos provocarem a planejar, executar e avaliar intervenções e interferências de ajuda, apoio e cuidado - educação escolar e/ou não escolar, do contrário, são meras rotulações que tendem a engessar o sujeito naquilo que o diagnóstico considera como falta (AMIRALIAN, 1986).

\section{Resultados e discussão}

Diante do exposto nos tópicos que fazem parte desse nosso artigo, que também visa - mais do que responder algo - problematizar e trazer à tona outras/novas inquietações, apresentamos nossos dados, que em alguns momentos refletem e em outros refratam os apresentados anteriormente, mas que contribuem para "manter a chama do debate acesa".

a) Infantilização da sexualidade dos estudantes com DI - "Sempre "ousas dizer o nome" de uma "flor" sempre infantil - do ingênuo, do bondoso".

As falas das professoras, nessa representação existencial, reforçam a ideia de que os estudantes com DI são seres angelicais, que não têm sexo e, que por isso, devem ser mantidos puros.

Professora 1: "Eu acho que nosso aluno tem sexo não! [risos] Tem, mas não o modo de expressar [risos] É uma espécie de anjinho ele ou ela, e por isso eu rezo sempre pra essas crianças".

Professora 2: "A última coisa que eu penso é sexo que esses alunos especiais podem ter...ter.... Não penso! Eles são puros demais, pra essas maldades".

Professora 3: "Minha ideia é que eles podem até ser sexualidade, mas eu não trabalho nunca isso. Não vejo necessidade, não vejo mesmo, é querer macular o outro".

Professora 4: "Eu vejo o aluno com deficiência intelectual como aquele que por ter essas perturbações precisa mais de mim ao lado dele ajudando-o e não o pervertendo. Nessa nossa sociedade doida, é bem possível se a gente 
http://dx.doi.org/10.5902/1984686X48341

resolver educar sexualmente alguém seria taxado de pedófilo, de doente. $\mathrm{O}$ aluno precisa de nossa ajuda".

Por essas respostas tão rígidas - nenhuma delas transitou entre uma ou outra RE aqui descrita em três - podemos antever que os dados coletados na revisão de literatura indicam a presença de preconceitos em lidar com a sexualidade de sujeitos discentes com DI, dividindo-os entre os bondosos e puros e maléficos e perversos.

Maia e Camossa (2002) reconhecem que a sexualidade da pessoa com deficiência é evidente e aponta que dependendo do grau dessa deficiência, pode influenciar a capacidade do sujeito de ter desejos e construir vínculos amorosos e sexuais. Porém, a maior dificuldade dessas pessoas não é a condição biológica ou intelectual, mas uma sociedade que tem dificuldade em conviver com as manifestações sexuais e aceitar como direito a educação sexual para elas. Parece mais seguro e menos comprometedor transformar os estudantes com DI em seres angelicais, pois de acordo com Freire (2005) educar é se comprometer.

As respostas, nesse tópico analisado, reportam a uma ideia de que a RE dos professores acerca da sexualidade de aluno com DI é de que ele é intocável por ser um sacrossanto e puro, no dizer de Giami (2004) um anjo. Um contexto que desvela uma sociedade com dificuldades em lidar com esse tema (MAIA; CAMOSSA, 2002; MAIA, 2001).

Assim é que a reza (ou a oração) religiosa aparece para apagar a culpa de nada fazer de concreto com o fato sexual, e descumprir recomendações dos Parâmetros Curriculares Nacionais de 1998, indo contra as propostas de intervenção, tal como proposto nos trabalhos de Suplicy et al. (1999), Costa (2000), Leão e Ribeiro (2007) e Prioste (2010).

A nomeação de santos e anjos aparece para retirar o conteúdo sexual dos alunos que deixam de ser humanos (já que assexualizados), indo em direção de parte das discussões de Giami (2004). Há o professor que simplesmente nega e diz que nem pensa. Não ousa tocar no tema. O tema não the diz respeito e nem ao aluno e ou aluna. Embora as representações dos professores sejam muito diferentes, Bastos e Deslandes (2005), ensinam que o desenvolvimento da sexualidade dos estudantes acontece igualmente, independentemente de ter ou não deficiência. Nessa RE de tornar invisível a sexualidade, o jovem é "coisa", é objeto - não é humano na sua autonomia diante do outro. Tornar-se-á subserviente, dominado, dependente, acossado dentro de um clima quase persecutório humano, mas desumanizado. Por isso, é um tema vital o estudo da relação professor-aluno, 
http://dx.doi.org/10.5902/1984686X48341

no que se refere ao desejo sexual e os modos éticos de lidar com essa complexidade que move os sujeitos na escola, permitindo um erotismo que seja canalizado para a aprendizagem, e com isso o desenvolvimento (PINEL, 2018).

A professora reconhece que os alunos e ou alunas "até" podem ser sexualizados, mas isso não aparece nas suas aulas; isso é negado, e ela faz uma travessia para um menino ou menina idealizado/a. Falando de sexo pode macular, ferir, contaminar. Então se ignora essa temática que poderia transitar pelo cotidiano escolar e até nas aulas propriamente ditas, no ensino de conteúdos educacionais.

Outra vez acontece de a professora entender a Educação Sexual planejada, executada e avaliada nas emergências do cotidiano escolar, onde mais o desejo parece vir à tona, como algo do descuidado, como perversão. O conteúdo que existe advindo como aspecto natural da sexualidade humana passa a ser descaracterizado. Há a denúncia de uma sociedade hipócrita que pode agir histericamente em "denuncismos" contra o mestre que opta por fazer um trabalho desses - há um medo, um sentimento persecutório.

b) Desumanização / julgamento da sexualidade dos estudantes com DI - "Sempre "ousa dizer o nome" do humano sem humanidade - do pecado, da tara".

As falas dos professores nessa RE produzem a imagem de um estudante com DI descontrolado, animalizado e selvagem, cuja demonstração da sexualidade precisa ser contida e o tema impedido na escola.

Professor 5: "Esses alunos são uns tarados [risos]. Se eu tocar no assunto eles se descontrolarão, e bem mais do que os normais que já aprontam. Minha representação é essa".

Professora 6: "Um dia desses eu peguei o Henrique [nome do aluno com Síndrome de Down - nome modificado por questões éticas da pesquisa] mexendo no "lepolepo" dele [no pênis; risos] no "bilauzinho" [risos]. Eu fiquei apavorada. Essa família não educa esse menino, não? Ele precisa de um psicólogo, eu falei com a coordenadora. Falei mesmo! Eu não dou conta de um desavisado desses... Ele sabe o que está fazendo, ele sabe que é imoral, ele tem consciência."

A Representação Existencial aqui-agora de professores com vivências com aluno e ou aluna com DI é de que se trata de alguém perverso, sorrateiro, supersexuado, um tarado, um pecador, um diabo, um demônio etc. Um descontrolado - a fera descrita por Giami (2004) que é um mito contra o aluno com DI e sua sexualidade como em Maia e Ribeiro (2010), Bastos e Deslandes (2005), e Moura e Cavalcanti (2014). Esse tipo de Guia de Sentido que vem a lume a partir da Representação Existencial está compatível com a ideia de Kropotkin (1998), no qual o jovem poderá se tornar aquilo que impregna a 
http://dx.doi.org/10.5902/1984686X48341

representação, qual seja perverso e outros adjetivos relacionados, discurso que humilha e diminui o sujeito, que pode evocar bullying.

Prioste (2010) enfatiza que as manifestações da sexualidade da pessoa com DI/DM são, muitas vezes, interpretadas (analisadas) como desvio de conduta, ao invés de serem percebidas como curiosidade e desejo de saber. Ela diz que as reações moralistas ganham escopo abafando a demanda de produzir debates e os esclarecimentos sobre o tema. A pesquisadora advoga acerca das possibilidades da educação sexual e o que pode emergir daí.

Há nessa RE do professor o discurso do populacho ("lepolepo", "bilauzinho", tarado) acerca da sexualidade do outro - seu aluno, sua aluna. Há o medo e o desespero do mestre diante do tema sexual, e então não raro eles fazem a recomendação de especialistas - que não eles mesmos - diagnostiquem e tratem dos distúrbios que eles acreditam que o aluno tenha. Assim, qualquer expressão sexual dos sujeitos diagnosticados como DI serão taxadas, pelos professores, como comportamentos de feras sem controle. Há uma responsabilização do sujeito com DI como aquele que malvadamente faz conscientemente tudo o que faz, porque assim o deseja.

É assertivo considerarmos nossa sociedade, em muitas situações, como repressora das expressões sexuais, ainda mais quando atua contra as expressões dos desejos que advêm de pessoas com DI, que acabam sendo consideradas "anormais", e não pessoas ou sujeitos de direito. Há assim um duplo temor dessa sociedade, muitas vezes classificada como moralista e hipócrita: medo das pessoas com DI, medo e pavor da expressão da sexualidade. A junção DI e expressão sexual funciona como uma metafórica bomba-relógio a explodir na cara da sociedade, causando mal-estar no que assim se denomina civilização.

O que é e como é ser jovem aluno com DI, no processo de ir se tornando pessoa, tendo como professor, um ser preconceituoso, que o considera como anjo e ou como demônio? Que tipo de jovem com DI está se educando ao ser assim, um professor? Como tais preconceitos produzem impacto nos modos de ser do ser no mundo do aluno com DI, estando eles envolvidos em um processo de ensino e aprendizagem de conteúdos escolares oficiais? Considerando que a categoria autoestima é indispensável para desenvolver e aprender, como essa situação vivida, impregna o ser mais profundo do jovem? Como esse jovem tem conseguido transcender a tais relações de rótulos negativos, o seu ser enfrenta(dor)? Como ele consegue resistir e/ou se fazer um ser da resiliência? 
http://dx.doi.org/10.5902/1984686X48341

Essas questões, entendemos, precisam ser problematizadas no cotidiano escolar e de modo clínico ou urgente, pois fazem parte do processo de humanização do ser humano.

c) Reconhecimento da sexualidade dos estudantes com DI como direito e parte do desenvolvimento humano saudável - "Sempre "ousas dizer o nome" um ser que está sempre em desenvolvimento - do ser aberto a mais aprendizagens de sentido".

Nessa terceira RE, o professor apresenta uma visão de sexualidade progressista, calcada nos direitos humanos e como parte constituinte de todas as pessoas, inclusive dos estudantes com DI.

\begin{abstract}
Professor 7: "Eu acho que é um aluno que precisa de nossa ajuda, e mais, eu destaco dessa ajuda justamente devido ele ter lá seus problemas, que a maioria não tem, a da deficiência mental - de fato até nós professores precisamos de cuidado [risos]. Eu mesmo conversei com o Henrique um dia desses sobre a masturbação dele na aula da Mirta (professora 5). Fui numa boa, ele estava mexendo no pênis dele também na minha aula... Eu não fiz escândalo, fiquei "na minha" e cheguei fundo, indo perto dele e o pedi que continuasse nas tarefas - as que eu propus à turma e que todos de um certo modo estavam envolvidos. Eu conversei e deixei muito ele conversar, mesmo ele tendo dificuldades de falar. O que ele faz pareceu-me um instinto, um impulso normal das pessoas, só que ele não tem controle - e ao mesmo tempo é um direito dele ter prazer. Dialogar pode ser um caminho para ensinar (e ele aprender) que na vida há limites que a própria sociedade coloca pra existir civilidade - e ao mesmo tempo recordar-lhe que é um sujeito de direitos. Para mim, enquanto professor, meu papel é dizer-se 'eu preciso dialogar sem temor, com paciência, persistência, com esperança'. Muita perseverança eu preciso ter, pois não é em uma 'conversinha' que tudo resolve, é preciso diálogo pra tentar começar uma procura de compreensão e ação".
\end{abstract}

O discurso buscado / valorizado, em nosso entendimento - compatível com a prática e novas percepções não preconceituosas acerca do discente com DI na sala de aula escolar - é o do professor 7, que se mostra compactuado com Moura e Cavalcanti (2014), inclusive quando reconhece que os professores demandam uma formação continuada nessa esfera - a das sexualidades deles também, como também mostrou Vieira (2012).

O professor 7 se aproxima do sentido do cuidado (cuidar/Sorge ${ }^{2}$ ), reconhecendo no sujeito suas demandas especiais e ao mesmo tempo diferenciadas, mas numa igualdade de direitos - indo além dos preconceitos, crenças, ideias distorcidas (MAIA, 2001; FURLANI, 2011; COSTA, 2000; LEÃO; RIBEIRO, 2007; PRIOSTE, 2010; SUPLICY et al., 1999).

Leão e Ribeiro (2007) indicaram, em sua revisão de literatura, sobre a orientação sexual num cenário inclusivo que há a necessidade do estudante vivenciar espaços de conhecimento de si (no mundo) destacando aí a sexualidade, para que se emancipem como 
http://dx.doi.org/10.5902/1984686X48341

cidadãos, aprendendo a denunciar mitos e tabus sobre o tema, especialmente quando os envolvem.

Também apontaram a necessidade de produzir e provocar (inventar) políticas públicas que garantam direitos individuais (no mundo). Na escola defendem a criação de programas educacionais evocadores de orientação/ educação sexual objetivando mudanças pessoais (sociais) que se atenham à relevância do tema sexualidade "[...] de modo que todos os estudantes inseridos nos bancos escolares possam desfrutar de uma educação inclusiva, a qual não exclua, mas sim inclua a sexualidade" (LEÃO; RIBEIRO, 2007, p. 1).

O professor 7 parece tomar para si os problemas que o professor 5 tem em lidar com a questão da masturbação na sala de aula. Ele então, aproveitando da mesma emissão comportamental do aluno Henrique, parte para uma ação pautada pelo diálogo, que ele diferencia de uma "conversinha", algo sem planejamento, na esfera do "disse me disse". O diálogo passa a ser, desse modo uma produção dialógica, um termo que denota interesse sincero pelo outro, por seu comportamento e subjetivação. Não desconhece a questão da pressão social e o processo civilizatório, as repressões que aí aparecem. Ao mesmo tempo em que é preciso ter o controle (o autocontrole junto ao outro no mundo) e desse espaço que se pode produzir a insubmissão pela aceitação das diferenças de ser um outro. A abordagem desse professor (FURLANI, 2011) talvez se encaixe numa visão de defesa dos direitos humanos e sexuais, com tendência emancipatória em um discurso que se aproxima a Paulo Freire (2005) pelo foco e valor que fornece ao diálogo e ao outro.

Costa (2000), ao desenvolver um programa de orientação sexual para jovens com deficiência, indica a potência que é construir parcerias com os estudantes que possibilitem discutir sobre os preconceitos, limitações impostas pela deficiência e os tabus relacionados ao sexo, de modo que possam ser desconstruídos.

A produção de oficinas de orientação sexual numa escola inclusiva é um trabalho positivo, que acabou por nos dar duas pistas indispensáveis nessa esfera da educação sexual de pessoas com DI: a de que a escola demanda articular-se com o conteúdo social, de modo crítico, emancipatório, e a de que, a partir daí, possamos entender e compreender "[...] o processo de construção histórico- social (da escola e da sociedade) para chegar ao ponto em que estão. Neste sentido é possível cogitar e trabalhar a sua transformação" (COSTA, 2000, p. 1).

O sentido de ser (sendo) humano indica-nos ser ele um ser mais, ou seja, um ser de relações em um contínuo processo de "vir-a-ser" nesse mesmo mundo de possibilidades. 
O ser mais, próprio do homem, é um termo voltado a buscar superação de práticas desumanizantes que enfatizam o sentir-se não ser, presente no processo histórico da humanidade.

O diálogo aqui-agora pode ser uma atuação político-pedagógica intencionada do professor objetivando a transformação dos limites da opressão social impostos contra as pessoas em seu processo do ato sentido de dizer o/do mundo. A intenção nessa Pedagogia é a de que toda pessoa pode assumir, de modo consciente e crítico, sua responsabilidade pelo contínuo devir do mundo com o outro, em um projeto interminável (e sempre sendo) de tornar-se mais e mais humano.

Diálogo então para Paulo Freire (2005) é o encontro entre pessoas mediatizadas pelo objeto de conhecimento, no desejo de produzir e reconstruir o conhecimento, sendo uma comunicação dialogal solidária entre homens democratizados, um ao lado do outro e imbricados na relação junto ao outro no mundo, donde emerge solidariedade de saberes entre ambos os sujeitos, intencionados a transformar o mundo - e com isso a si próprios.

Trata-se de dialogar com a energia sexual do discente, uma força motriz dos movimentos humanos socialmente valorizados. Um momento pedagógico e psicopedagógico em que o jovem discente pode reavaliar seu existir, ser feliz sem submeter-se, ser feliz junto ao outro no mundo. No diálogo os homens "buscam a afirmação como sujeitos de decisão, todos estes movimentos refletem o sentido mais antropológico do que antropocêntrico de nossa época” (FREIRE, 2005, p. 31).

\section{(In) conclusões}

A Deficiência Intelectual (DI) e a sexualidade de jovens têm sido reconhecidas como experiências com as quais professores e educadores podem desvelar dificuldades em lidar na sala de aula escolar, assim como no ambiente não escolar. Tais problemáticas dos mestres podem ser alguns dos impeditivos para se promover efetivamente a inclusão. Diante do exposto, o objetivo desse artigo foi 0 de descrever $e$ analisar fenomenologicamente as "Representações Existenciais/ RE" (PINEL, 2012) de professores/professoras de uma escola pública capixaba, acerca da sexualidade de seus/ suas discentes jovens diagnosticados/diagnosticadas, em seus laudos médicos e psicológicos, com Deficiência Intelectual. Para produzir essas RE foi vital efetuar uma investigação fenomenológica. Diante dos dados que fazem parte desse artigo, são problematizadas e estimuladas outras/ novas inquietações acerca da capacidade humana 
http://dx.doi.org/10.5902/1984686X48341

diante de temáticas que podem ser tão complexas, dependendo de como lidamos com a sexualidade humana e a nossa própria.

Entre os sujeitos da pesquisa, professores de escolas públicas, que trabalham com jovens alunos com DI, não ocorreram respostas intercambiáveis entre os três tipos detectados na pesquisa. Foram respostas rígidas que não fizeram nenhum tipo de travessia entre os três tipos de representações existenciais. Uma travessia entre Deus (bondade, anjo - ser assexuado), diabo (perversão, maldade - ser hipersexuado) e a Terra do Sol (compreensão da sexualidade como algo comum aos seres humanos; ser do desenvolvimento e da aprendizagem sexual).

O professor 7, em uma produção discursiva esperada de um profissional do ensino e aprendizagem escolar, chega, de certo modo, a criticar a rigidez advinda das representações existenciais de que o menino/menina e sua sexualidade na sala de aula é o diabo ou deus, anjo ou demônio, bandido e mocinho - dicotomizando a Representação Existencial do seu existir junto ao discente com DI e sua sexualidade.

Os professores - a maioria - assim se desvelaram rígidos e fechados, carecendo, provavelmente, de uma formação continuada que proporcione a eles mesmos falar de suas vidas sexuais e sentir numa escuta perante a sexualidade do outro, permitindo suas expressões como algo humano, algo que pertence e compõe essa humanidade, que é dele, do aluno, da família, da comunidade.

É importante reconhecer que a formação inicial tem suas limitações de tempo e de currículo e, em muitas situações, não dará conta de abarcar todos os saberes e a diversidade humana que uma sala de aula pode apresentar. Nesse caso, nos apoiamos em Freire (2005) e reconhecemos que os seres humanos, e aqui os educadores, são seres inconclusos e em processo de constituição, na dialética do existir.

De acordo com os PCNs sobre orientação sexual para o ensino fundamental (BRASIL, 1998), a sexualidade é parte integrante da vida e da saúde dos seres humanos e se manifesta desde o nascimento até a morte. Além de estar presente, o tempo inteiro, no ambiente escolar, não se limitando às portas de banheiro e nem a qualquer ideia do senso comum que defenda a possibilidade de deixá-la em casa.

Nesse contexto, defendemos a urgência de as Secretarias de Educação municipais e estaduais, possivelmente em parceria com universidades e institutos federais, oferecerem capacitações voltadas às temáticas de gênero, sexualidade e orientação sexual, pois como já foi exposto, o Relatório Mundial sobre Deficiência (OMS, 2011) indicou que a educação 
http://dx.doi.org/10.5902/1984686X48341

sexual colabora para o desenvolvimento saudável e que pessoas com deficiência, principalmente as com DI, estão mais expostas à situações de abuso sexual.

Quando um tema "toca" tanto a pele do professor como é a sexualidade do aluno com DI, é bem-vinda uma formação que afeta, donde o formador escuta empaticamente e ao mesmo tempo, de modo ativo, coloque provocações, humanizando as dores (e as alegrias), os preconceitos, os estigmas, os tabus, criando/ inventando coletivamente pontes de transformação de seres duros em maleáveis, que desrespeitam para seres respeitadores, de punidores para pessoas abertas, aceitadoras.

Fazer travessias da rigidez para flexibilidade e abertura ao inusitado daquele humano em sala de aula, cuja demanda é receber ensino e aprender, pode ajudá-lo a desenvolverse mais, aprender mais.

\section{Referências}

AMIRALIAN, Maria Lúcia T. M. Psicologia do excepcional. São Paulo: EPU, 1986.

BRASIL. Lei n. 13.146, de 6 de jul. de 2015. Lei Brasileira de Inclusão da Pessoa com Deficiência. Disponível em: http://www.planalto.gov.br/ccivil_03/_ato20152018/2015/lei/l13146.htm. Acesso: 17 de set. 2020.

BRASIL. Secretaria de Educação Fundamental. Parâmetros Curriculares Nacionais: terceiro e quarto ciclos: apresentação dos temas transversais. Brasília: MECSEF, 1998.

BASTOS, Olga Maria; DESLANDES, Suely Ferreira. Sexualidade e o adolescente com deficiência mental: uma revisão bibliográfica. Ciência \& saúde coletiva, Rio de Janeiro, v. 10, n², p. 389-397. Jun. 2005. Disponível em:

https://www.scielo.br/scielo.php?script=sci_arttext\&pid=\$1413-81232005000200017. Acesso em: 05 jan. 2020.

BEIRAS, Adriano; TAGLIAMENTO, Grazielle; TONELI, Maria Juracy Filgueiras. Crenças, valores e visões: trabalhando as dificuldades relacionadas a sexualidade e gênero no contexto escolar. Aletheia. Canoas, n. 21, p. 69-78, jun. 2005. Disponível em: http://pepsic.bvsalud.org/scielo.php?script=sci_arttext\&pid=S1413-03942005000100007. Acesso em: 23 dez. 2019.

COSTA, Juliana da Silva. Educação inclusiva e orientação sexual: dá para combinar? Psicologia: ciência e profissão. Brasília, vol. 20, n.1, p. 50-57, mar. 2000. Disponível em: https://www.scielo.br/scielo.php?pid=S1414-

98932000000100007\&script=sci_arttext\&tlng=pt. Acesso em: 18 dez. 2020.

DRAGO, Rogério et al. Estudos e pesquisas sobre síndromes; relatos de casos. Rio de Janeiro: WAK, 2013. 
DRAGO, Rogério. A criança com deficiência mental causada pela síndrome Rubinsteintaybi: inclusão e escolarização. In: III CONGRESSO INTERNACIONAL "EDUCAÇÃO INCLUSIVA E EQUIDADE”. 3. 2013, Almada. Anais eletrônicos. Almada: Pró-inclusão, 2013. p. 236 - 253. Disponível em:

http://congressopinandee2013.weebly.com/uploads/1/6/4/6/16461788/doc4-

textos_completos_2_-parte_ii_-_pp_800_a_1620.pdf. Acesso em: 15 de out. 2020.

DRAGO, Rogério; PINEL, Hiran. Alunos com síndromes raras na escola comum; um olhar fenomenológico-existencial. Revista Linhas Críticas. Brasília, DF: v. 20, n. 43, p. 605627, set./ dez. 2014. Disponível em:

https://periodicos.unb.br/index.php/linhascriticas/article/view/4395. Acesso em: 18 fev. 2020.

DRAGO, Rogério; COLODETE, Paulo Roque; PINEL, Hiran. Um tema que "não ousas"; deficiência mental, representação existencial. In: RODRIGUES, Alexsandro; DALLAPÍCULA, Catarina; RODRIGO, Sérgio Rodrigo da S. (Org.). Transposições; sexualidade e educação. 2ed. Vitória: Edufes, 2015, v. 1, p. 125-149.

ERTHAL, Tereza Cristina S. Treinamento em psicoterapia vivencial. Petrópolis: Vozes, 1994.

FOUCAULT, Michel. Doença mental e Psicologia. Rio de Janeiro: Tempo Brasileiro, 1975.

FORGHIERI, Yolanda Cintrão. Psicologia Fenomenológica. São Paulo: Pioneira, 2001.

FREIRE, Paulo. Pedagogia do oprimido. Rio de Janeiro: Paz e Terra, 2005.

FURLANI, Jimena. Educação sexual na sala de aula. Belo Horizonte: Autêntica, 2011.

GIAMI, Alain. O anjo e a fera: sexualidade, deficiência mental e instituição. São Paulo: Casa do Psicólogo, 2004.

GOFFMAN, Erving. Manicômios, Prisões e Conventos. São Paulo: Editora Perspectiva, 2001.

HENRY, Carl Ferdinand, Howard. Deus, revelação e autoridade. 15 teses. Vol. 2, parte 1. São Paulo: Agnos, 2017.

KEMPTON, Marc Winifred. Sexuality and mental retardation: a review of the literature. In CRAFT, Ann; CRAFT, Michael. Sex education and couselling for mentally handicapped people.Tunbridge Wells: Costelo, 1983.

KROPOTKIN, Pietr. Palavras de um revoltado. São Paulo: Ícone Editora, 2005.

LEÃO, Andreza Marques de Castro; RIBEIRO, Paulo Rennes Marçal. A orientação sexual no contexto inclusivo; um estudo teórico. Revista Ibero-Americana de Estudos em

Educação. Araraquara, Vol. 2, n², p. 1-9, abr. 2007. Disponível em:

http://seer.fclar.unesp.br/iberoamericana/article/view/465/345. Acesso em: 15 jan. 2020. 
MAIA, Ana Cláudia Bortolozzi. Reflexões sobre a educação sexual da pessoa com deficiência. Revista Brasileira de Educação Especial. Marília, v.7, n.1, 2001. p. 35-46. Disponível em:

https://www.abpee.net/homepageabpee04_06/artigos_em_pdf/revista7numero1pdf/3bortol ozzi_maia.pdf. Acesso em 18 jan. 2020.

MAIA, Ana Cláudia Bortolozzi; CAMOSSA, Denise do Amaral. Relatos de jovens deficientes mentais sobre a sexualidade através de diferentes estratégias. Paidéia. Ribeirão Preto. vol.12, n. 24, p. 205-214, 2002. Disponível em: https://www.scielo.br/scielo.php?script=sci_arttext\&pid=S0103863X2002000300009\&lng=pt\&tlng=pt. Acesso em: 08 nov. 2019.

MAIA, Ana Cláudia Bortolozzi; RIBEIRO, Paulo Rennes Marça. Desfazendo mitos para minimizar o preconceito sobre a sexualidade de pessoas com deficiências. Rev. Bras. Ed. Esp., Marília, v.16, n.2, p.159-176, Mai.- Ago, 2010. Disponível em:

https://www.scielo.br/scielo.php?pid=S1413-

65382010000200002\&script=sci_abstract\&tlng=pt. Acesso em: 03 dez. 2020.

MOURA, Elizabeth Santiago; CAVALCANTI, Tícia Cassiany Ferro. Educação Inclusiva: Sexualidade e Deficiência Intelectual. 2014. Disponível em:

https://www.ufpe.br/ce/images/Graduacao_pedagogia/pdf/2010.1/educao\%20inclusi va\%20sexualidade\%20e\%20deficincia\%20intelectual.pdf. Acesso em: 18 dez. 2019.

OMS - ORGANIZAÇÃO MUNDIAL DA SAÚDE. Relatório Mundial Sobre a Deficiência. 2011. Governo do Estado de São Paulo. Secretaria dos Direitos da Pessoa com Deficiência. Disponível em: https://apps.who.int/iris/bitstream/handle/10665/44575/9788564047020_por.pdf;jsessi onid=DD915E1341A3C83AD7BE5AF6844B2D57? sequence=4. Acesso em: 15 de set. 2020.

PINEL, Hiran. Educação especial \& klínica-ká: algumas questões históricas, princípios, métodos... São Paulo: Clube de Autores, 2012.

PINEL, Hiran, et al. Pedagogia hospitalar; um enfoque fenomenológico existencial. São Paulo: Clube de Autores, 2015.

PINEL, Hiran. Representação Existencial de "ser no mundo", o encarnado e método fenomenológico de pesquisa; experiências na classe hospitalar. Vitória: Do autor, 2018.

PRIOSTE, Cláudia Dias. Educação inclusiva e sexualidade na escola; relato de caso.

Estilos da Clínica. São Paulo, Vol. 15, n 1, p. 14-25, 2010. Disponível em: http://pepsic.bvsalud.org/scielo.php?script=sci_arttext\&pid=S1415-71282010000100002. Acesso em: 23 nov. 2019.

SAFRANSKI, Rüdiger. Heidegger; um mestre da Alemanha entre o bem e o mal. São Paulo: Geração Editorial, 2005.

SUPLICY, Marta; et al. Sexo se aprende na escola. São Paulo: Olhos D’água, 1999. 
VASCONCELOS, Marcio Moacyr de. Retardo mental. Jornal de Pediatria. Porto Alegre. Vol. 80, № 2, p. (Supl), 2004. Disponível em:

https://www.scielo.br/pdf/jped/v80n2s0/v80n2Sa09.pdf. Acesso em: 14 dez. 2019.

VIEIRA, Alexandro Braga. Currículo e educação especial; as ações da escola a partir dos diálogos cotidianos. Tese. 326 p. Doutorado em Educação. Universidade Federal do Espírito Santo. Vitória, 2012.

VOEGELIN, Eric. Reflexões autobiográficas. São Paulo: É Realizações editora, 2008.

\section{Notas}

1 Não encontramos o termo "representação existencial" como o definimos e ou os modos como ainda o estamos a pesquisar, e muito menos, estudos e práticas educacionais aplicadas aos estudos da pessoa com DI e outras deficiências, autismos, altas habilidades, sujeito gravemente enfermos, com dislexia, com transtornos da atenção concentrada e seletiva, com neurose e psicose, com problemas comportamentais na escola e fora dela etc., muito menos focando na percepção de seus professores quanto ao tema da sexualidade. Autores como o teólogo David Jenkins (HENRY, 2017, p. s/p), o existencialista e teólogo Tillich (2005, p. 686), Voegelin (2008, p. 105) - dentre outro "falam" de "representação existencial". Estamos produzindo um artigo para diferenciar nossas propostas e outras, como citadas nessa nota de rodapé, mas a nossa é frontalmente indissociada a uma Clínica Existencial (ERTHAL, 1994) e Psicologia FenomenológicoExistencial aplicada à Educação Especial Escolar e Não Escolar, centrando-se em uma clínica que valoriza os desvios, os desencontros, as resistências, as resiliências, percebendo fenomenologicamente a saúde nesse vivido/ experienciado negativo e ou positivo, cabendo a responsabilidade do sujeito pela produção/ invenção de um "projeto de ser" como "ser no mundo", dentro de sua "liberdade inquestionável".

2 O termo alemão "Sorge", utilizado por Heidegger em "Ser e Tempo" pode ser compreendida como ternura, cuidado, atenção, em como preocupação que é "uma marca fundamental da conditio humana" (SAFRANSKI, 2005, p. 198).

\section{Correspondência}

Hiran Pinel - Universidade Federal do Espírito Santo, Centro de Educação - CE, Av. Fernando Ferrari, 514, prédio IC IV, Campus Goiabeiras, Vitória, Espírito Santo - Brasil.

CEP: $29060-900$

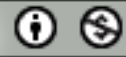

This work is licensed under a Creative Commons Attribution-NonCommercial 4.0 International (CC BY-NC 4.0) 